\title{
Room-temperature single-photon emitters in titanium dioxide optical defects
}

\author{
Kelvin Chung ${ }^{* 1}$, Yu H. Leung ${ }^{2,3}$, Chap H. To², Aleksandra B. Djurišić ${ }^{2}$ \\ and Snjezana Tomljenovic-Hanic ${ }^{1}$
}

\author{
Full Research Paper \\ Address: \\ ${ }^{1}$ School of Physics, The University of Melbourne, Parkville, VIC 3010 , \\ Australia, ${ }^{2}$ Department of Physics, The University of Hong Kong, \\ Pokfulam Road, Hong Kong and ${ }^{3}$ Current address: The Nano and \\ Advanced Materials Limited (NAMI), Science Park, Hong Kong \\ Email: \\ Kelvin Chung* - kelvin.chung@unimelb.edu.au \\ * Corresponding author \\ Keywords: \\ fluorescence; optical defects; room temperature; single-photon \\ emitters; titanium dioxide
}

Beilstein J. Nanotechnol. 2018, 9, 1085-1094. doi:10.3762/bjnano.9.100

Received: 04 January 2018

Accepted: 06 March 2018

Published: 04 April 2018

Associate Editor: A. J. Meixner

(C) 2018 Chung et al.; licensee Beilstein-Institut. License and terms: see end of document.

\begin{abstract}
Fluorescence properties of crystallographic point defects within different morphologies of titanium dioxide were investigated. For the first time, room-temperature single-photon emission in titanium dioxide optical defects was discovered in thin films and commercial nanoparticles. Three-level defects were identified because the $g^{(2)}$ correlation data featured prominent shoulders around the antibunching dip. Stable and blinking photodynamics were observed for the single-photon emitters. These results reveal a new room-temperature single-photon source within a wide bandgap semiconductor.
\end{abstract}

\section{Introduction}

Single-photon sources offer non-classical states of light [1] and are a prerequisite for future quantum technologies [2]. There are many types of single-photon emitters that include molecules [3], trapped atoms [4], quantum dots [5] and defects in diamond [6]. More recently point defects of wide-bandgap semiconductors, such as zinc oxide ( $\mathrm{ZnO})$ [7-9] and silicon carbide [10], were shown to exhibit room-temperature single-photon emission. $\mathrm{ZnO}$ is the only metal oxide reported to host single-photon emitting defects at room temperature and was recently shown to exhibit stable fluorescence when uptaken into skin cells, making it a viable biomarker [11].
Titanium dioxide $\left(\mathrm{TiO}_{2}\right)$ is a well-studied wide-bandgap semiconductor, its production cost is low and it is used as a white pigment in foods, cosmetics [12], textiles [13] and paints [14]. It has a relatively high refractive index of 2.3 at $550 \mathrm{~nm}$ [15] and recent work demonstrated its potential applications as novel optical material for waveguides and resonators [16-21]. $\mathrm{TiO}_{2}$ can be fabricated using many methods resulting in an abundance of nanostructures [22]. In nanoparticle form, $\mathrm{TiO}_{2}$ is a constituent of sunscreens $[23,24]$. Other applications also include elimination of environmental pollution [25-28], and energy [29] and sensing applications [30-32]. Semiconductor 
defects have been touted as an promising platform for the development of a quantum computer in the solid state [33] in which the usage of $\mathrm{TiO}_{2}$ could be possible with further research into its quantum and physical properties.

$\mathrm{TiO}_{2}$ crystallises into three main forms: anatase, rutile and brookite [34]. Defects can be introduced during fabrication or are intrinsic to the crystallographic structure. Extensive work on $\mathrm{TiO}_{2}$ surface defects [35] has come from the need to progress catalytic reactions. Point defects within the $\mathrm{TiO}_{2}$ include interstitials and vacancies [36-38].

The defects are responsible for visible photoluminescence (PL) in $\mathrm{TiO}_{2}$ and have been observed in thin films [39-41], nanocrystals/nanoparticles [42-47], nanorods [48], nanotubes [49-51], nanosheets [52], nanoribbons [53] and fibres [54]. In material sciences, the PL spectrum of a sample is obtained by large spot size excitations, e.g., Amekura et al. investigated the PL from $\mathrm{ZnO}$ nanoparticles with a spot size of approximately $4 \mathrm{~mm}$ $[55,56]$. This spot size constitutes an ensemble measurement where PL from many defects is sampled. Therefore, single defects and their emission peaks cannot be resolved. As a comparison, the spot size used to excite the defects in this work was $280 \mathrm{~nm}$.

This paper presents exploratory optical studies of various $\mathrm{TiO}_{2}$ morphologies. For the first time, defects in $\mathrm{TiO}_{2}$ thin films and nanopowders exhibited single-photon emission. Standard characterisation measurements of fluorescence microscopy, correlation measurements, PL spectra and photodynamics are presented.

\section{Experimental}

\section{Electron-beam deposition of $\mathrm{TiO}_{2}$ thin films}

The films were fabricated via e-beam deposition in high vacuum with the substrate temperature set to $200{ }^{\circ} \mathrm{C}$ during deposition. Subsequently, the samples were left untreated ("non-annealed"), or were annealed in air in a tube furnace at two temperatures: 450 and $850{ }^{\circ} \mathrm{C}$. The ramping rate of the furnace was $5{ }^{\circ} \mathrm{C} / \mathrm{min}$. These samples are labelled $\mathrm{NA}-\mathrm{TiO}_{2}$, a-450 ${ }^{\circ} \mathrm{C}-\mathrm{TiO}_{2}$, and $850{ }^{\circ} \mathrm{C}-\mathrm{TiO}_{2}$. A fourth film sample was also fabricated in a similar manner except that the substrate temperature was set to $160{ }^{\circ} \mathrm{C}$ and annealed at $450{ }^{\circ} \mathrm{C}$ in the same manner as a-450 ${ }^{\circ} \mathrm{C}-\mathrm{TiO}_{2}$. This sample is labelled b-450 ${ }^{\circ} \mathrm{C}-\mathrm{TiO}_{2}$.

\section{Preparation of $\mathrm{TiO}_{2}$ nanopowder samples}

Two nanopowder phases, anatase and rutile (MTI Corporation) were used. The anatase (rutile) has a purity of $99 \%$ with an average particle size of $30 \mathrm{~nm}(45 \mathrm{~nm})$. Four nanopowder samples were prepared: anatase and rutile suspended in deionised (DI) water, and anatase and rutile suspended in isopropyl alcohol (IPA). For the nanopowder-DI water mixture, $21.0(20.6) \pm 0.2 \mathrm{mg}$ of anatase (rutile) nanopowder was suspended in $10 \mathrm{~mL}$ of DI water. Similarly for the nanopowder-IPA mixture, $19.9(20.1) \pm 0.2 \mathrm{mg}$ of anatase (rutile) was suspended into $10 \mathrm{~mL}$ of IPA. The mixtures were ultrasonicated for $5 \mathrm{~min}$ to disperse the nanopowder evenly into both DI water and IPA yielding concentrations of approximately $2 \mathrm{mg} / \mathrm{mL}$.

Each mixture was dripped with a pipette onto a silicon wafer whilst on a hotplate $\left(60-90{ }^{\circ} \mathrm{C}\right)$ to evaporate the solvent, leaving a layer of nanopowder. This was repeated until an obvious white layer on top of the wafer was deposited. Smaller amounts of nanopowder can be used, but as it will be seen in the section "Results and Discussion", it is preferable to obtain a clear indication of deposited nanopowder on the substrate.

\section{Confocal microscopy}

Figure 1 is a schematic of the scanning confocal microscope used to investigate the $\mathrm{TiO}_{2}$ defects. The samples were illumi-

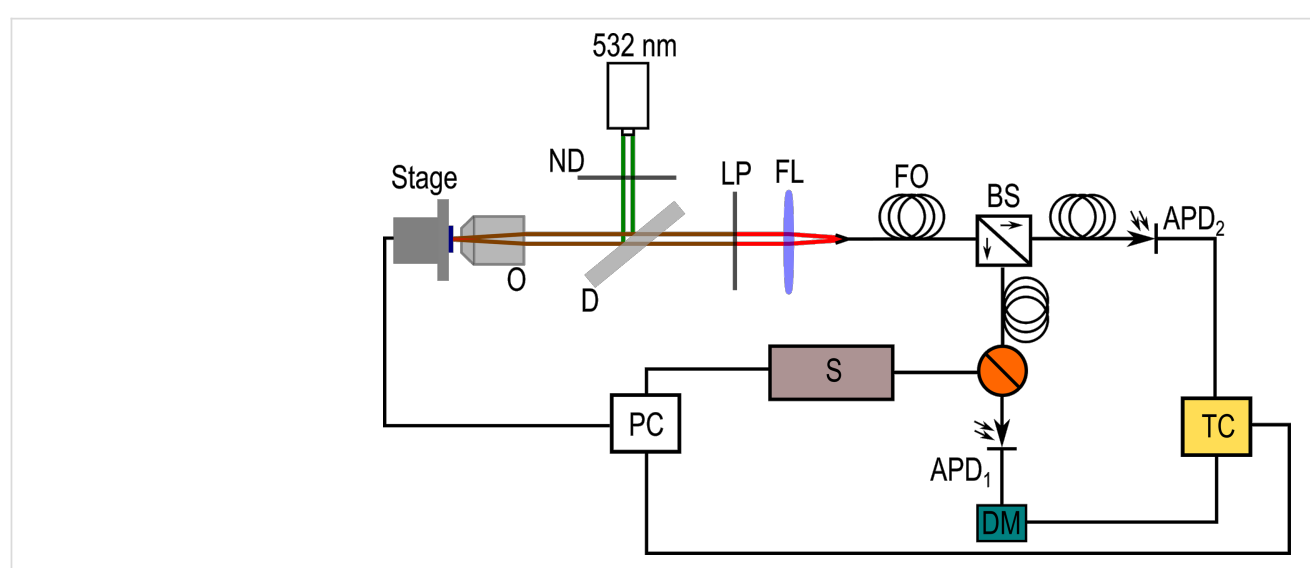

Figure 1: The experimental setup of the scanning confocal microscope used for investigating $\mathrm{TiO}_{2}$ defects. 
nated by a frequency-doubled Nd:YAG laser $(\lambda=532 \mathrm{~nm})$ the intensity of which was controlled with a neutral density filter (ND). The laser is reflected off a dichroic mirror (DM) and focussed onto the sample with a $100 \times(0.95 \mathrm{NA})$ air objective (O). The lateral resolution and diffraction-limited spot size was approximately $280 \mathrm{~nm}$ (in the plane of the substrate). The sample is mounted on a piezoelectric controlled stage with $100 \mu \mathrm{m}$ travel. The fluorescent light is recollected through $\mathrm{O}$ and passes through a $560 \mathrm{~nm}$ long-pass filter (LP) to filter out the excitation laser. A converging lens (FL) focusses the fluorescent light into an optical fibre (FO), which acts as the confocal pinhole. The fluorescence signal is fibre-optically split 50:50 (BS) incident upon two avalanche photodiodes $\left(\mathrm{APD}_{1,2}\right.$, Perkin Elmer SPCM-AQRH-14-FC: timing resolution $=350 \mathrm{ps}$ at $825 \mathrm{~nm}$ ). The system can be switched (orange junction) between two main configurations for taking spectra (S) and performing Hanbury Brown-Twiss (HBT) interferometry, which uses a delay module (DM) and a time-correlated single-photon counting system (TC). A computer (PC) was used to control the stage, spectrometer and correlation data acquisition parameters.

\section{Results and Discussion Confocal microscopy of various $\mathrm{TiO}_{2}$ morphologies}

The various $\mathrm{TiO}_{2}$ samples were investigated at room temperature using scanning confocal microscopy. This form of microscopy allows for high-resolution images that resolve fluorescence signals from individual defects. The motivation in exploring different $\mathrm{TiO}_{2}$ morphologies was to determine if room-temperature single-photon emitters exist. Figure 2 shows representative $100 \times 100 \mu \mathrm{m}^{2}$ confocal scans of the $\mathrm{TiO}_{2}$ samples including thin films, single crystal and nanopowders. The films were synthesized as described above, single crystals and nanopowders were purchased (MTI Corporation).

Thin films annealed at various temperatures, NA-TiO ${ }_{2}$, a-450 ${ }^{\circ} \mathrm{C}-\mathrm{TiO}_{2}, \mathrm{~b}-450{ }^{\circ} \mathrm{C}-\mathrm{TiO}_{2}$ and $850{ }^{\circ} \mathrm{C}-\mathrm{TiO}_{2}$, were investigated. The expected $\mathrm{TiO}_{2}$ phases were an amorphous phase in the untreated sample, anatase in $\mathrm{a}-450{ }^{\circ} \mathrm{C}-\mathrm{TiO}_{2}$ and rutile in $850{ }^{\circ} \mathrm{C}-\mathrm{TiO}_{2}$ [57]. The confocal scans in Figure $2 \mathrm{a}-\mathrm{d}$ show fluorescent features in all samples. The untreated and $450{ }^{\circ} \mathrm{C}$
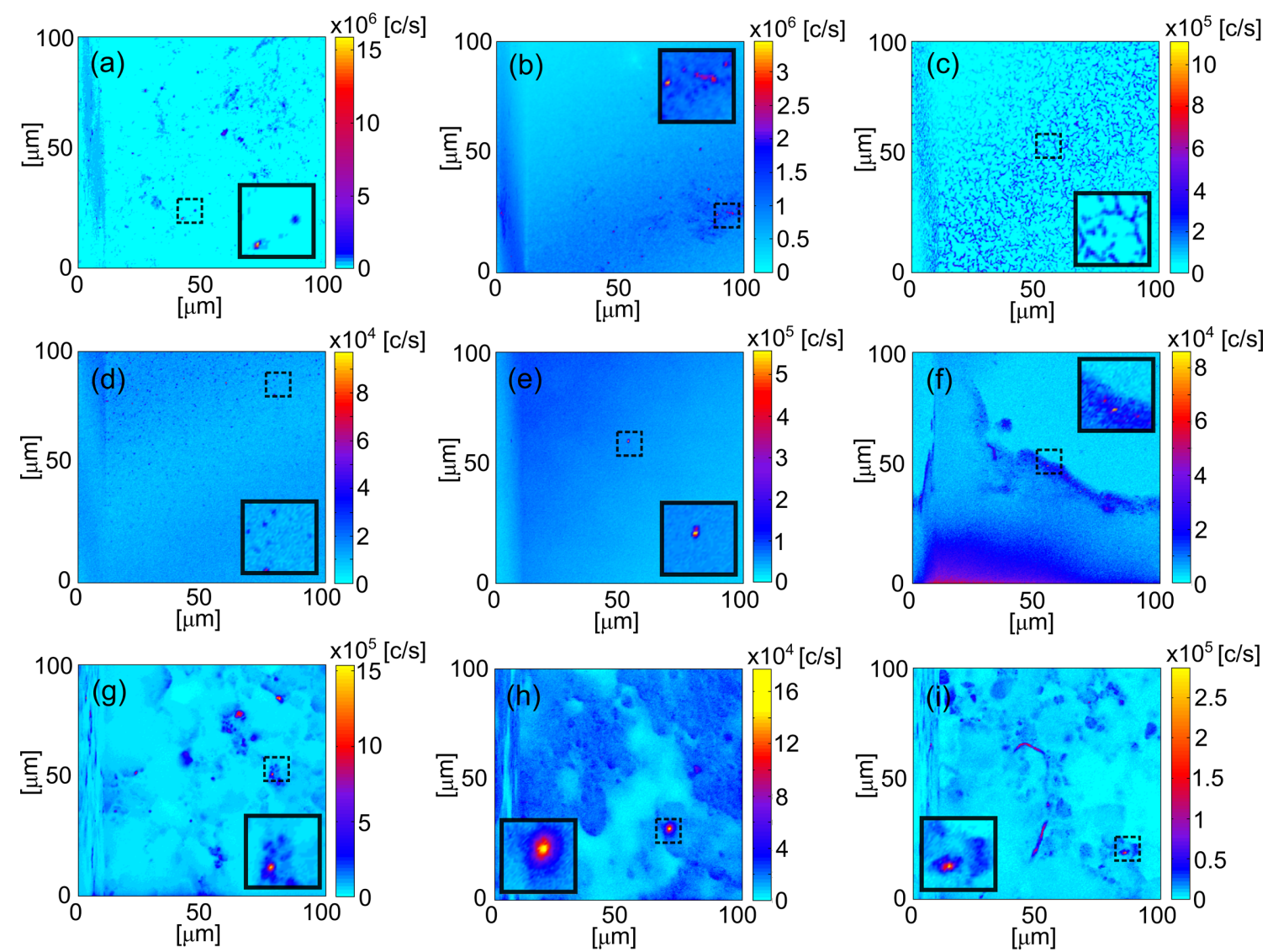

Figure 2: Representative $100 \times 100 \mu \mathrm{m}^{2}$ confocal scans of $\mathrm{TiO}_{2}$ morphologies. E-beam deposited thin films: (a) $\mathrm{NA}-\mathrm{TiO}_{2}$, (b) a-450 ${ }^{\circ} \mathrm{C}-\mathrm{TiO}_{2}$,

(c) $850{ }^{\circ} \mathrm{C}-\mathrm{TiO}_{2}$ and (d) b-450 ${ }^{\circ} \mathrm{C}-\mathrm{TiO}_{2}$. (e) Single crystal rutile $(001)$ with edges of $\langle 100\rangle$. Nanopowder samples: (f) rutile + DI water; (g) anatase + DI water; (h) rutile + IPA and (i) anatase + IPA. The colour bars represent the count rate at the detector for each sample. The solid line black box represents the magnified region of the dashed line black box with $10 \times 10 \mu \mathrm{m}^{2}$ area. 
films show point-like fluorescent features, whereas the $850{ }^{\circ} \mathrm{C}$ reveals filament-like fluorescent structures. The total area scanned for each thin film sample was approximately $1 \times 1 \mathrm{~cm}^{2}$.

The single-crystal rutile was $10 \times 10 \times 1.0 \mathrm{~mm}^{3}$ in size. It had an orientation of (001) with edges of $\langle 100\rangle$, and a purity greater than $99.99 \%$. Figure $2 \mathrm{e}$ is a representative confocal scan and is devoid of fluorescent features.

Anatase and rutiles nanopowders were dispersed into water and IPA. Figure $2 \mathrm{f}-\mathrm{i}$ show fluorescent features from point-like objects alongside large areas of contrast, due to defects within the nanopowders and residue of the solvent, respectively. The total area scanned for each nanopowder sample was approximately $0.5 \times 0.5 \mathrm{~cm}^{2}$.

Each sample was investigated for fluorescing defects, which were further examined for single-photon emission by observing its photon statistics. Once a single-photon emitter was identified, the defect was characterised by obtaining its PL spectrum and recording the photodynamics of its count trace. Fluorescence was observed in all the morphologies. However, singlephoton emission was only observed in two morphologies, the characterisation of these single-photon emitting defects is presented in the next two subsections.

The single-crystal $\mathrm{TiO}_{2}$ morphology was produced via the floating-zone growth process. The production of $\mathrm{TiO}_{2}$ nanoparticles in industry involves wet chemical processes. For both morphologies, thermal treatment is also required. To the best of our knowledge, we can only conclude that we did not observe single-photon emission in some morphologies probably due to different fabrication methods and annealing temperatures. It can be inferred that for these two morphologies there is a pure nonradiative decay mechanism. This topic is beyond the scope of the current work, which focusses on the optical regime and single-photon emission. Morfa et al. [7] observed a dependence of the creation of defects in $\mathrm{ZnO}$ nanoparticles on the annealing temperature.

\section{Single-photon emission in $\mathrm{TiO}_{2}$ thin films}

The a- $450{ }^{\circ} \mathrm{C}-\mathrm{TiO}_{2}$ sample exhibited single-photon emission. For a given arbitrary coarse scan of $100 \times 100 \mu \mathrm{m}^{2}$, fluorescence spots were observed to be sparse in character. Figure 3 shows characteristic $10 \times 10 \mu \mathrm{m}^{2}$ confocal scans of the sample. Two defects, $\mathrm{D}_{1}$ and $\mathrm{D}_{2}$, were identified and characterised. The defects were found during unique coarse scans, which were separated in distance by hundreds of micrometres.

$D_{1}$ and $D_{2}$ were not necessarily the brightest defects in the scans with much larger count rates observed for other fluorescent features. The other bright features could be other defects or contaminations. Defects $\mathrm{D}_{1}$ and $\mathrm{D}_{2}$ had their fluorescence monitored via a HBT interferometer to quantify their photon statistics. For a single-photon emitter, the second-order correlation function needs to satisfy the inequality: $g^{(2)}(\tau=0)<0.5$, where $\tau$ is the delay time electronically imposed to one of the detectors in the HBT setup. For $\mathrm{D}_{1}$, a three-level model was chosen to fit normalised $g^{(2)}$ data. It has the form $[6,58]$ : $g^{(2)}(\tau)=A-B \cdot \exp \left(-\kappa_{21}\right) \tau+C \cdot \exp \left(-\kappa_{23 / 31}\right) \tau$, where $A, B$ and $C$ are fitting coefficients. The excited state and non-radiative decay rates are represented by $\kappa_{21}$ and $\kappa_{23 / 31}$, respectively. An appropriate fit to all parameters was achieved by minimising the least squares error between the three-level model and the normalised $g^{(2)}$ data. This fit is shown in the inset of Figure $4 \mathrm{a}$. At $\tau=0$, the second-order correlation function was $0.40 \pm 0.05$, which satisfies the inequality for a single-photon emitter, i.e., the emission events were antibunched. At a pump power of $82 \pm 1 \mu \mathrm{W}$, the excited and non-radiative lifetimes were calculated to be $0.52 \pm 0.01 \mathrm{~ns}$ and $25.88 \pm 5.25 \mathrm{~ns}$, respectively. The normalised $g^{(2)}$ data was smoothed (moving average filter) before the lifetimes were calculated. The coefficients of the
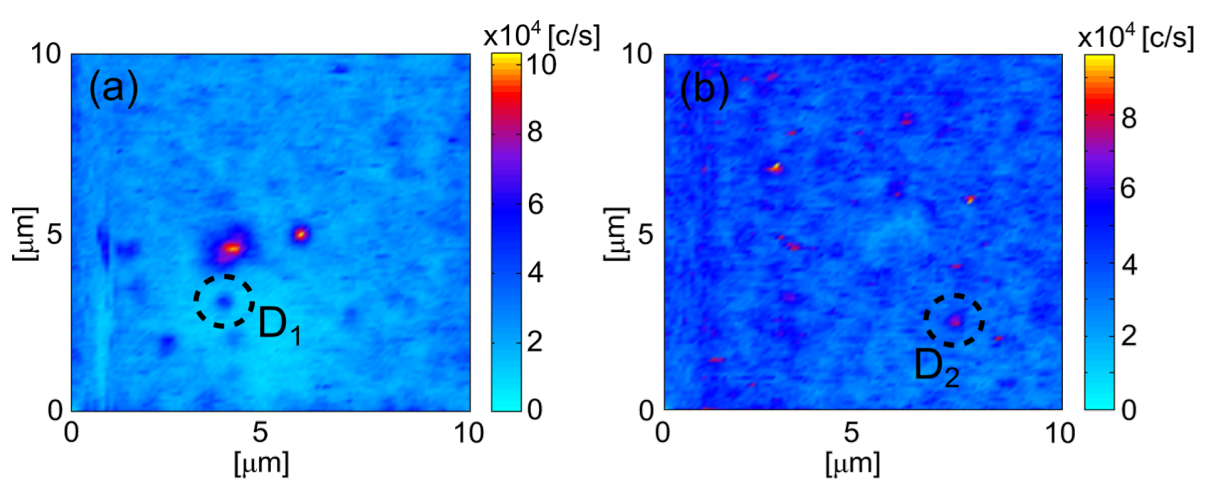

Figure 3: $10 \times 10 \mu \mathrm{m}^{2}$ confocal scans of two single-photon emitters (a) defect $\mathrm{D}_{1}$ and (b) defect $\mathrm{D}_{2}$ found on the a-450 ${ }^{\circ} \mathrm{C}-\mathrm{TiO}{ }_{2}$ sample. The colour bars represent the count rate at the detector. 

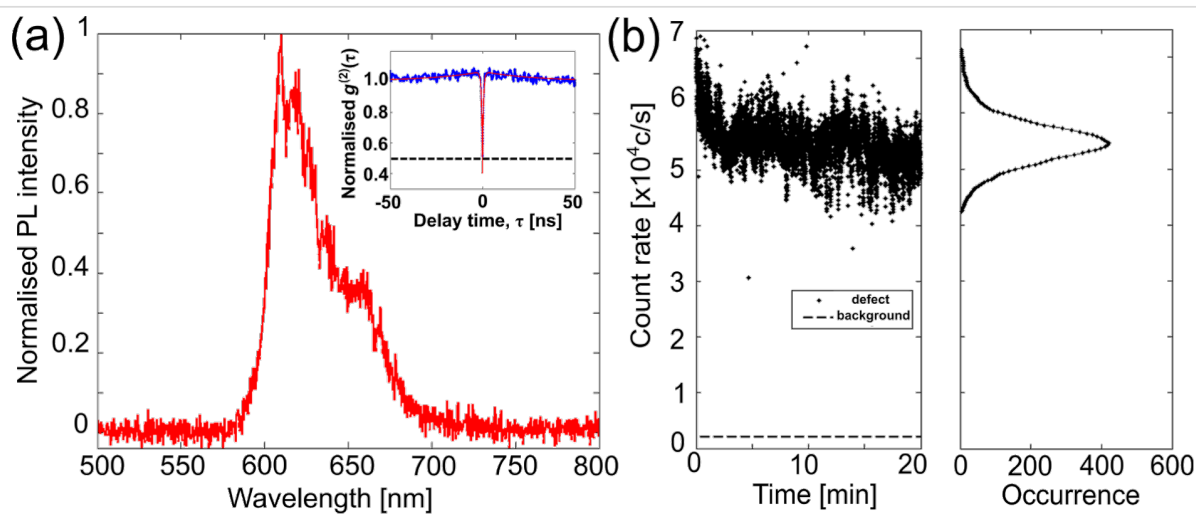

Figure 4: Characterisation results of defect $\mathrm{D}_{1}$, shown in Figure $3 a$, found in the a- $450{ }^{\circ} \mathrm{C}-\mathrm{TiO}_{2}$ sample. (a) Normalised $\mathrm{PL}$ intensity with an inset of the normalised $g^{(2)}$ data (blue points) with a three-level model fit (red line) at $82 \pm 1 \mu \mathrm{W}$ pump power. The time bin was 64 ps, with an integration time of $1200 \mathrm{~s}$, the count rates at the detectors was $41.7 \times 10^{3}$ and $40 \times 10^{3} \mathrm{c} / \mathrm{s}$ with a background of $2 \times 10^{3} \mathrm{c} / \mathrm{s}$. The dashed line represents the normalised $g^{(2)}(\mathrm{T})=0.5$. (b) The count trace and histogram for $82 \mu \mathrm{W}$ pump power. This histogram had the count rate binned into $511 \mathrm{c} / \mathrm{s}$. The background count rate is indicated by the dashed line.

three-level model $\left(A, B, C, \kappa_{21}\right.$ and $\left.\kappa_{23 / 31}\right)$ were determined by minimising the least squared error between the model and normalised data. These lifetimes are comparable to singlephoton emission of $\mathrm{ZnO}$ defects [7-9].

Upon confirmation of single-photon emission, the PL spectrum of $\mathrm{D}_{1}$ was acquired and can be seen in Figure $4 \mathrm{a}$. The PL spectrum of the defect shows red fluorescence between 600 and $700 \mathrm{~nm}$. There were three resolvable peaks at 610,619 and $630 \mathrm{~nm}$. Red fluorescence has been attributed to undercoordinated $\mathrm{Ti}^{3+}$ ions in atomic layer deposited films [41], electrons trapped at surface defect sites [59] and surface oxygen vacancies on anatase nanocrystal films [60]. Similar photoluminescence in the red was also observed from $\mathrm{ZnO}$ defects [7-9].

The photodynamics of $\mathrm{D}_{1}$ was also recorded and can be seen for a pump power of $82 \mu \mathrm{W}$ in Figure $4 \mathrm{~b}$. The time trace shows photostability with no obvious fluorescence intermittency, i.e., blinking. Subsequent measurements of $\mathrm{D}_{1}$ could not be conducted beyond $118 \mu \mathrm{W}$ due to the defect photobleaching. This was confirmed by re-scanning the area of interest during which the original bright spot on the confocal image, indicative of a fluorescing defect, had ceased to the background count rate $\left(3 \times 10^{3} \mathrm{c} / \mathrm{s}\right)$. A histogram of the count rates at $118 \mu \mathrm{W}$ shows a peak frequency above the background count rate. This behaviour can only be due to photoionisation of $\mathrm{D}_{1}$. The fluorescence photostability was different from previous works on $\mathrm{ZnO}$ defects in which fluorescence intermittency was observed [7-9].

The characterisation of $\mathrm{D}_{1}$ was only partially completed because the defect photobleached during data acquisition. Therefore, an intrinsic lifetime could not be determined. Only one $\mathrm{D}_{1}$-type defect was observed in this study. It was not antici- pated that the defect would photobleach at such low pump powers. However, for defect $\mathrm{D}_{2}$ bleaching did not occur and the intrinsic lifetimes could be calculated. The correlation data of defect $\mathrm{D}_{2}$ was fitted with a three-level model and the inset of Figure $5 \mathrm{~b}$ shows a fit at a pump power of $293 \mu \mathrm{W}$. The excitedstate $\left(\mathrm{R}_{\mathrm{LT}}\right)$ and non-radiative $\left(\mathrm{NR}_{\mathrm{LT}}\right)$ lifetimes were calculated for various pump powers incident upon $\mathrm{D}_{2}$ and are shown in Figure 5a.

Linear fits of the lifetimes as a function of pump power allows for the calculation of the intrinsic lifetimes, which are represented by the zero-power intercept. The linear fits omit the pump powers of 99 and $148 \mu \mathrm{W}$ due to their poor statistics, there was a large variance in the correlation data away from the centre of the antibunching dip. A moving average filter was applied to the data to obtain a smooth response to assist with the fitting, without success. Therefore, the two low pump powers were considered to be outliers. The intrinsic lifetimes were calculated using pump powers of 200, 250 and $293 \mu \mathrm{W}$. The intrinsic excited-state and non-radiative lifetimes were calculated to be $0.58 \mathrm{~ns}$ and $72.44 \mathrm{~ns}$, respectively. These values are similar to values of $\mathrm{ZnO}$ defects [7]. Figure $5 \mathrm{~b}$ is the spectrum of $\mathrm{D}_{2}$, which shows red fluorescence between 575 and $800 \mathrm{~nm}$ with a broad peak centred around $640 \mathrm{~nm}$. Compared to the spectrum of $D_{1}$ it has different spectral features, which means that $\mathrm{D}_{1}$ and $\mathrm{D}_{2}$ are two chemically different defects.

Figure $5 \mathrm{c}$ is the count trace and histogram observed for $\mathrm{D}_{2}$ at $99.0 \pm 0.5 \mu \mathrm{W}$ pump power exhibiting relative photostability. When the power is increased to $148.0 \pm 0.5 \mu \mathrm{W}$, the defect exhibits blinking between two distinct levels of an "off" and an "on" state, i.e., a ground state and a bright state, which can be seen in Figure $5 \mathrm{~d} . \mathrm{D}_{2}$ showed robustness to permanent photoionisation, it did not photobleach after a long data acquisi- 

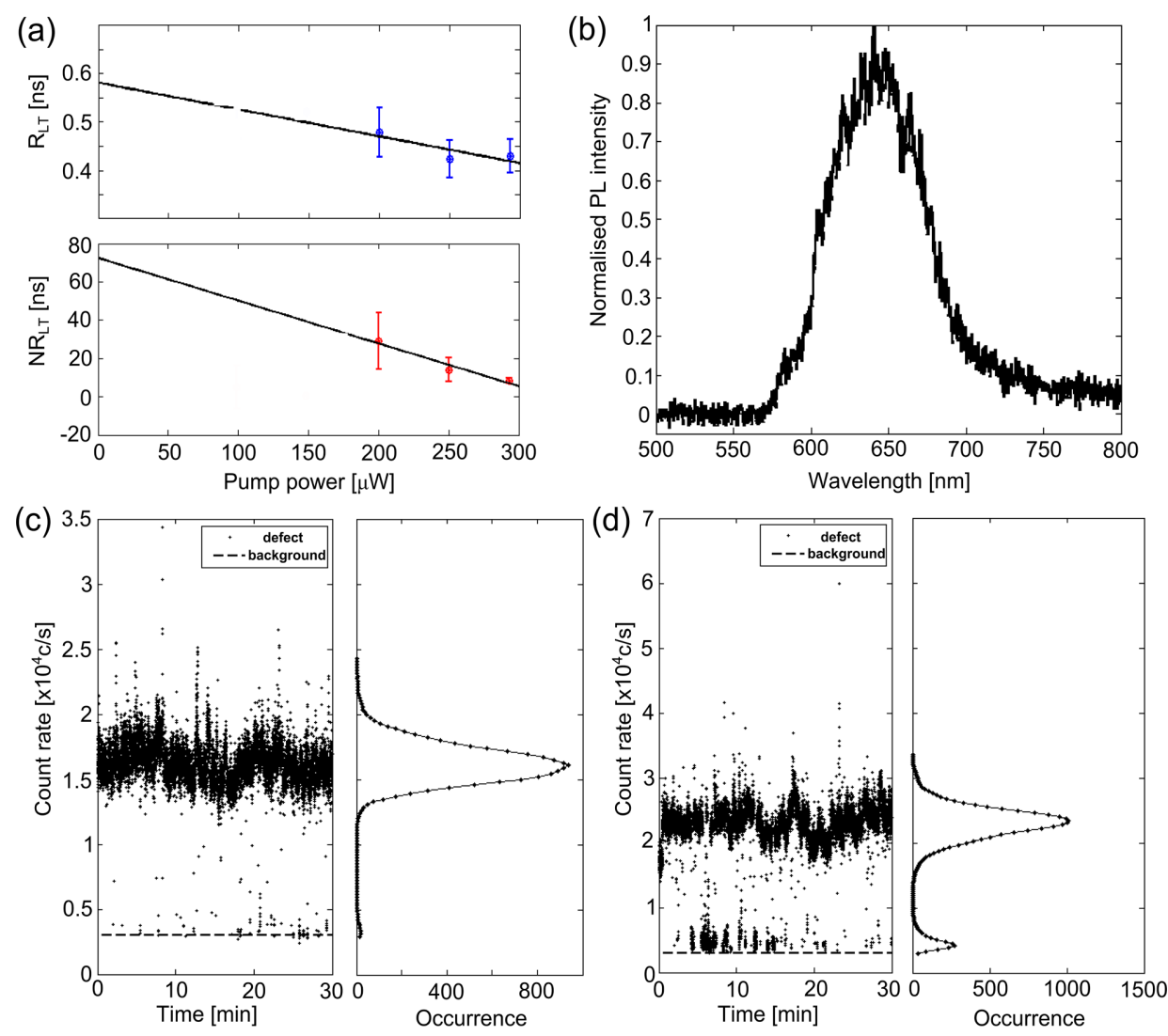

Figure 5: Characterisation results of defect $D_{2}$. (a) The excited-state $\left(R_{L T}\right)$ and non-radiative $\left(N R_{L T}\right)$ lifetimes calculated using a three-level model (with $95 \%$ confidence intervals in the uncertainty bars). The black line represents a linear fit for the intrinsic lifetimes using pump powers of 200,250 and $293 \mu \mathrm{W}$. (b) Normalised PL intensity. The time traces and histograms at pump powers: (c) $99 \pm 0.5 \mu \mathrm{W}$ (histogram binned into $308 \mathrm{c} / \mathrm{s}$ ),

(d) $148 \pm 0.5 \mu \mathrm{W}$ (histogram binned into $533 \mathrm{c} / \mathrm{s}$ ). The dashed line represents the background count rate of $3 \times 10^{3} \mathrm{c} / \mathrm{s}$.

tion period totalling $3 \mathrm{~h}$. Furthermore, the photodynamics for $\mathrm{D}_{2}$ show a contrast to the behaviour of $\mathrm{D}_{1}$, which indicates that different defects were obtained in the films. It must be noted, that single-photon emitters in the $\mathrm{a}-450{ }^{\circ} \mathrm{C}-\mathrm{TiO}_{2}$ sample were quite rare given the many fluorescing features on a $100 \times 100 \mu \mathrm{m}^{2}$ scan. Investigating many circular-like fluorescing features within a smaller region of $10 \times 10 \mu \mathrm{m}^{2}$, qualitatively, the $\mathrm{D}_{1}$ and $\mathrm{D}_{2}$ defects were the only features to exhibit single-photon emission. These two single-photon emitting defects represent $5 \%$ of the total number of fluorescing features investigated.

A previous work by Morfa et al. [7] on single-photon emitting defects in $\mathrm{ZnO}$ films showed that the annealing temperature plays an important role in the creation of defects. In our work, the films that were not annealed and those annealed at $850{ }^{\circ} \mathrm{C}$ exhibited no single-photon emission.

\section{Single-photon emission in $\mathrm{TiO}_{2}$ nanopowders}

Single-photon emission was also observed in the sample of anatase nanopowder and IPA (see Figure $2 \mathrm{i}$ for a representative confocal scan). The defect shown in Figure 6a was found to exhibit single-photon emission with $g^{(2)}(0)=0.17 \pm 0.04$. The normalised $g^{(2)}$ data was fit with a three-level model (Figure $6 \mathrm{~b}$, inset) and the excited-state and non-radiative lifetimes were calculated to be $0.46 \mathrm{~ns}$ and $19.49 \mathrm{~ns}$, respectively, similar to single-photon emitters in a- $450{ }^{\circ} \mathrm{C}-\mathrm{TiO}_{2}$ films. A three-level system was used because there were prominent shoulders around the antibunching dip in the normalised $g^{(2)}$ data. Interestingly, the confocal map of the single-photon emitting defect in the nanopowder shows the possibility of two entities. It can be seen there are two distinct spots, this is a unique feature to the nanopowder and is not evident in the other single emitters presented in this study.

Figure $6 \mathrm{~b}$ is the spectrum of the defect, which shows red emission with a peak around $629 \mathrm{~nm}$. The low signal-to-noise ratio was counteracted by increasing the exposure time at each step for the range of 550-1000 $\mathrm{nm}$. The complete spectrum was combined from three separate exposures. The exposure time was set to $120 \mathrm{~s}$. Longer times were not used but due to the chance of the defect permanently photobleaching at longer 

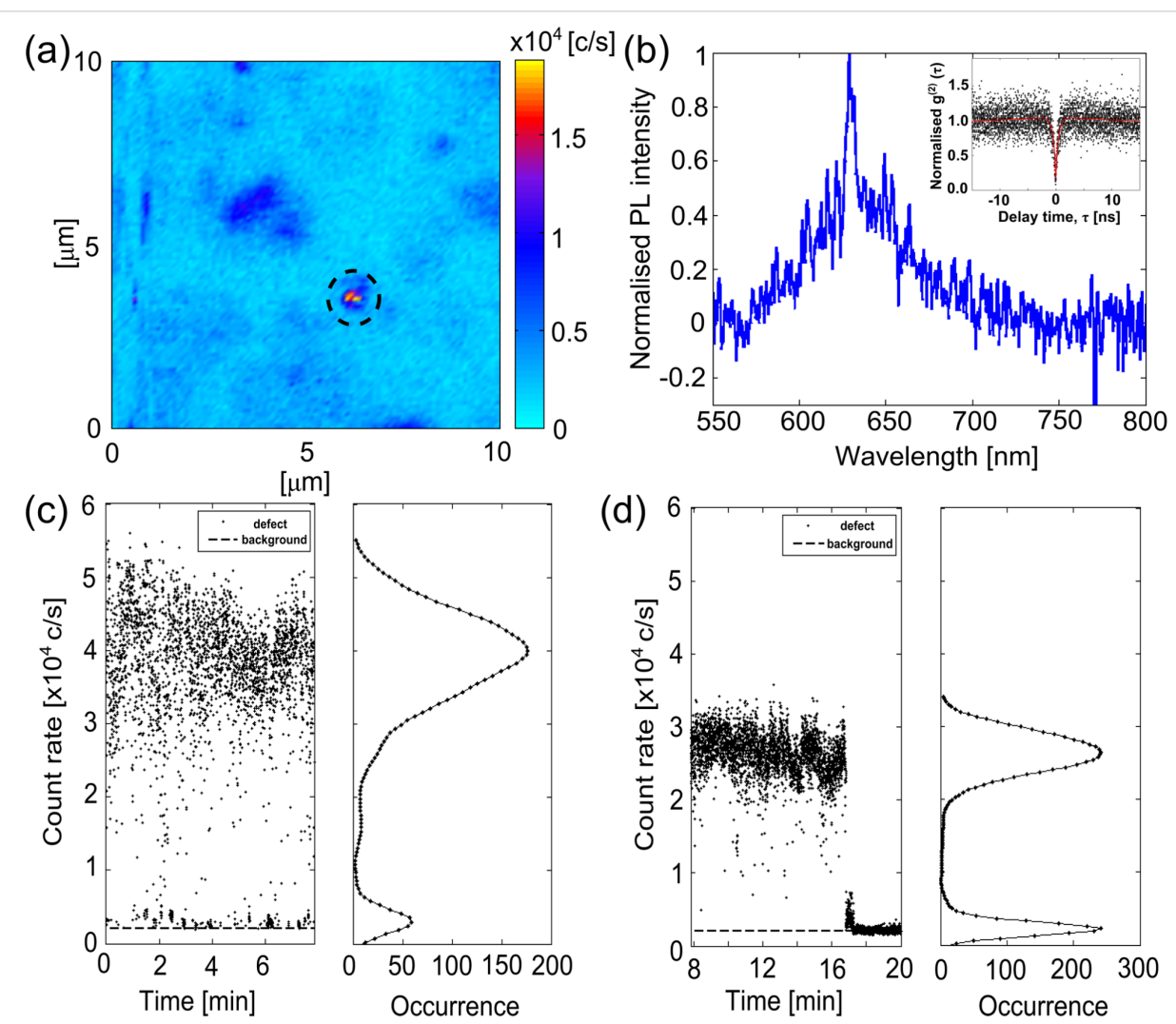

Figure 6: Characterisation results of a defect found in the sample of $\mathrm{TiO}_{2}$ anatase nanopowder and IPA. (a) $10 \times 10 \mu \mathrm{m}^{2}$ confocal scan indicating the defect with a dashed circle. The colour bar represents the count rate at the detector. (b) Normalised PL spectrum with an inset of a three-level model fit (red line) of the normalised $g^{(2)}$ data (black points). The fit parameters had count rates of $25.0 \times 10^{3} \mathrm{c} / \mathrm{s}$ and $24.5 \times 10^{3} \mathrm{c} / \mathrm{s}$ at each detector, a background count rate of $2 \times 10^{3} \mathrm{c} / \mathrm{s}$ and integration time of $1200 \mathrm{~s}$. (c, d) Count traces and histograms of the single-photon emitter for two periods of time (0-8 min and 8-20 min, respectively). The histograms in (c) and (d) were binned into $982 \mathrm{c} / \mathrm{s}$ and $505 \mathrm{c} / \mathrm{s}$, respectively. The background count rate is indicated by the dashed line. The pump power for the results in panels $b-d$ was $41.9 \pm 0.1 \mu \mathrm{W}$.

exposure times. The emission bandwidth matches the previous defects found on films. It is typical for the sub-bandgap excitation at $532 \mathrm{~nm}$ wavelength used here. Previous work by Mathew et al. [61] on $\mathrm{TiO}_{2}$ anatase colloidal nanoparticles has shown fluorescence spectra with distinct emission peaks in the visible spectrum between 400 and $600 \mathrm{~nm}$. Mathew et al. also attributed their visible emission to surface states originating from oxygen vacancies associated with $\mathrm{Ti}^{3+}$ ions. The work of Zhang et al. [42] on anatase nanocrystals fabricated through a chemical process could not conclude definitively the origin of their broad visible emission band centred around $578 \mathrm{~nm}$. They attributed it to the surface defects without an assignment of chemical origin.

Count traces and histograms shown in Figure 6c,d reveal that the defect blinks between two distinct "off" and "on" states from 0 to $8 \mathrm{~min}$ and remains relatively stable between 8 and $17 \mathrm{~min}$, followed by a permanent bleaching from 17 to $20 \mathrm{~min}$. The change in the maximum count rate just before and after the $8 \mathrm{~min}, 4 \times 10^{4} \mathrm{c} / \mathrm{s}$ and $2.6 \times 10^{4} \mathrm{c} / \mathrm{s}$, suggests that the first excited state was permanently photoionised and that after $8 \mathrm{~min}$ the defect had changed to a new electronic configuration. The data shown in Figure 6 was the only defect found that exhibited single-photon emission in the anatase nanoparticles.

The reason for the noisy spectrum and normalised $g^{(2)}$ was the relatively low maximum count rate. At a pump power of $41.9 \pm 0.1 \mu \mathrm{W}$, the maximum count rate was $35 \times 10^{3} \mathrm{c} / \mathrm{s}$ for the single-photon emitter. A low pump power was chosen for two reasons: (1) to be in the low-power regime when calculating the lifetimes; and (2) to prevent inadvertent photobleaching. We observed that many potential circular features would readily photobleach at pump powers of hundreds of microwatts or above.

The coupling efficiency can be increased for both morphologies that exhibit single-photon emission. For defects within thin films, a photonic cavity structure can be engineered around the single emitters and the spontaneous emission rate can be increased via the Purcell effect. $\mathrm{TiO}_{2}$ has already been shown to be a photonic cavity material [16,19-21,62-64]. For defects within nanoparticles, the emission rate can be increased by en- 
capsulation with material having a refractive index greater than that of air [65].

The issue of native defects in oxides is generally very complex. While the molecular formation and energy structures of defects have been previously discussed in the literature, a majority of these studies is concerned with catalytic and photocatalytic applications $[34,66]$. Therefore, the majority of existing research is focussed on obtaining defects that result in absorption in the visible spectral range. Then again, works on defects in $\mathrm{TiO}_{2}$ have been scarce. While some works have associated visible luminescence with specific defects [67], the obtained emission spectra are very broad, covering the entire visible spectral range.

At this stage, we cannot attribute a particular defect to the three bands observed. Future work would focus on the identification of the origin of the defects via density functional theory. In addition, the low probability of defects needs to be addressed to increase the number of defects formed during the fabrication process. Also, liquid nitrogen measurements may also reveal stronger signals in the emission peaks by suppressing the contributions due to phonon sidebands.

\section{Conclusion}

This study investigated thin films, single crystals and nanopowders of $\mathrm{TiO}_{2}$ via confocal microscopy. For the first time, it has been observed that $\mathrm{TiO}_{2}$ defects exhibit antibunching behaviour within thin films and anatase nanoparticles. This shows that $\mathrm{TiO}_{2}$ defects are a room-temperature single-photon source. The excited-state and non-radiative lifetimes were found to be within the range of several nanoseconds and tens of nanoseconds, respectively. The fluorescence occurred in the red emission band. The photodynamics of the defects ranged from photostable to blinking between two excited states. Future work would require optimisation of the growth conditions to increase the statistical prevalence of the fluorescent defects. This confocal microscopy study of $\mathrm{TiO}_{2}$ morphologies allows for the emission from individual defects to be resolved. This is essential for determining the chemical origin of the defects, which is subject of future work. These results pave the way to progress the studies into $\mathrm{TiO}_{2}$ as a material that hosts room-temperature single-photon emitters for practical quantum applications.

\section{Acknowledgements}

K.C. would like to acknowledge Melbourne Research Scholarship awarded by The University of Melbourne. S. T.-H. acknowledges an ARC Australian Research Fellowship (DP1096288). A. B. D. acknowledges financial support from the Seed Funding for Basic Research, The University of Hong Kong. We would also like to thank A. H. Piracha for additional help in annealing $\mathrm{TiO}_{2}$ thin film samples and D.A. Simpson for helpful discussion concerning the manuscript.

\section{ORCID ${ }^{\circledR}$ iDs}

Aleksandra B. Djurišić - https://orcid.org/0000-0002-5183-1467 Snjezana Tomljenovic-Hanic - https://orcid.org/0000-0002-4287-5564

\section{References}

1. Lounis, B.; Orrit, M. Rep. Prog. Phys. 2005, 68, 1129-1179. doi:10.1088/0034-4885/68/5/R04

2. O’Brien, J. L.; Furusawa, A.; Vučković, J. Nat. Photonics 2009, 3, 687-695. doi:10.1038/nphoton.2009.229

3. Lounis, B.; Moerner, W. E. Nature 2000, 407, 491-493. doi:10.1038/35035032

4. Kuhn, A.; Hennrich, M.; Rempe, G. Phys. Rev. Lett. 2002, 89, 067901. doi:10.1103/PhysRevLett.89.067901

5. Santori, C.; Pelton, M.; Solomon, G.; Dale, Y.; Yamamoto, Y. Phys. Rev. Lett. 2001, 86, 1502-1505. doi:10.1103/PhysRevLett.86.1502

6. Brouri, R.; Beveratos, A.; Poizat, J.-P.; Grangier, P. Opt. Lett. 2000, 25, 1294-1296. doi:10.1364/OL.25.001294

7. Morfa, A. J.; Gibson, B. C.; Karg, M.; Karle, T. J.; Greentree, A. D.; Mulvaney, P.; Tomljenovic-Hanic, S. Nano Lett. 2012, 12, 949-954. doi:10.1021/nl204010e

8. Jungwirth, N. R.; Pai, Y. Y.; Chang, H. S.; Macquarrie, E. R.; Nguyen, K. X.; Fuchs, G. D. J. Appl. Phys. 2014, 116, 043509 doi:10.1063/1.4890979

9. Neitzke, O.; Morfa, A.; Wolters, J.; Schell, A. W.; Kewes, G.; Benson, O. Nano Lett. 2015, 15, 3024-3029. doi:10.1021/nl504941q

10. Castelletto, S.; Johnson, B. C.; Ivády, V.; Stavrias, N.; Umeda, T.; Gali, A.; Ohshima, T. Nat. Mater. 2014, 13, 151-156. doi:10.1038/nmat3806

11. Chung, K.; Karle, T. J.; Khalid, A.; Abraham, A. N.; Shukla, R.; Gibson, B. C.; Simpson, D. A.; Djurišić, A. B.; Amekura, H.; Tomljenovic-Hanic, S. Nanophotonics 2016, 6, 269-278. doi:10.1515/nanoph-2015-0138

12. Weir, A.; Westerhoff, P.; Fabricius, L.; Hristovski, K.; von Goetz, N. Environ. Sci. Technol. 2012, 46, 2242-2250. doi:10.1021/es204168d

13. Bozzi, A.; Yuranova, T.; Guasaquillo, I.; Laub, D.; Kiwi, J. J. Photochem. Photobiol., A 2005, 174, 156-164. doi:10.1016/j.jphotochem.2005.03.019

14. Braun, J. H.; Baidins, A.; Marganski, R. E. Prog. Org. Coat. 1992, 20 , 105-138. doi:10.1016/0033-0655(92)80001-D

15. Wang, Z.; Helmersson, U.; Käll, P.-O. Thin Solid Films 2002, 405, 50-54. doi:10.1016/S0040-6090(01)01767-9

16. Subramania, G.; Lee, Y.-J.; Brener, I.; Luk, T. S.; Clem, P. G. Opt. Express 2007, 15, 13049-13057. doi:10.1364/OE.15.013049

17. Furuhashi, M.; Fujiwara, M.; Ohshiro, T.; Tsutsui, M.; Matsubara, K.; Taniguchi, M.; Takeuchi, S.; Kawai, T. AIP Adv. 2011, 1, 032102. doi:10.1063/1.3615716

18. Bradley, J. D. B.; Evans, C. C.; Choy, J. T.; Reshef, O.; Deotare, P. B.; Parsy, F.; Phillips, K. C.; Lončar, M.; Mazur, E. Opt. Express 2012, 20, 23821-23831. doi:10.1364/OE.20.023821

19. Choy, J. T.; Bradley, J. D. B.; Deotare, P. B.; Burgess, I. B.; Evans, C. C.; Mazur, E.; Lončar, M. Opt. Lett. 2012, 37, 539-541. doi:10.1364/OL.37.000539

20. Paunoiu, A.; Moirangthem, R. S.; Erbe, A. Phys. Status Solidi RRL 2015, 9, 241-244. doi:10.1002/pssr.201510012 
21. Reshef, O.; Shtyrkova, K.; Moebius, M. G.; Griesse-Nascimento, S.; Spector, S.; Evans, C. C.; Ippen, E.; Mazur, E. J. Opt. Soc. Am. B 2015, 32, 2288-2293. doi:10.1364/JOSAB.32.002288

22. Chen, X.; Mao, S. S. Chem. Rev. 2007, 107, 2891-2959. doi:10.1021/cr0500535

23. Nohynek, G. J.; Lademann, J.; Ribaud, C.; Roberts, M. S. Crit. Rev. Toxicol. 2007, 37, 251-277. doi:10.1080/10408440601177780

24. Newman, M. D.; Stotland, M.; Ellis, J. I. J. Am. Acad. Dermatol. 2009, 61, 685-692. doi:10.1016/j.jaad.2009.02.051

25. Chen, J.; Liu, M.; Zhang, L.; Zhang, J.; Jin, L. Water Res. 2003, 37, 3815-3820. doi:10.1016/S0043-1354(03)00332-4

26. Hashimoto, K.; Irie, H.; Fujishima, A. Jpn. J. Appl. Phys. 2005, 44, 8269-8285. doi:10.1143/JJAP.44.8269

27. Li, Q.; Mahendra, S.; Lyon, D. Y.; Brunet, L.; Liga, M. V.; Li, D.; Alvarez, P. J. J. Water Res. 2008, 42, 4591-4602. doi:10.1016/j.watres.2008.08.015

28. Daghrir, R.; Drogui, P.; Robert, D. Ind. Eng. Chem. Res. 2013, 52, 3581-3599. doi:10.1021/ie303468t

29. Chen, X. Chin. J. Catal. 2009, 30, 839-851. doi:10.1016/S1872-2067(08)60126-6

30. Choi, Y. J.; Seeley, Z.; Bandyopadhyay, A.; Bose, S.; Akbar, S. A. Sens. Actuators, B 2007, 124, 111-117. doi:10.1016/j.snb.2006.12.005

31. Zheng, J.; Li, G.; Ma, X.; Wang, Y.; Wu, G.; Cheng, Y. Sens. Actuators, B 2008, 133, 374-380. doi:10.1016/j.snb.2008.02.037

32. Buvailo, A. I.; Xing, Y.; Hines, J.; Dollahon, N.; Borguet, E. ACS Appl. Mater. Interfaces 2011, 3, 528-533. doi:10.1021/am1011035

33. Weber, J. R.; Koehl, W. F.; Varley, J. B.; Janotti, A.; Buckley, B. B.; Van de Walle, C. G.; Awschalom, D. D. Proc. Natl. Acad. Sci. U. S. A. 2010, 107, 8513-8518. doi:10.1073/pnas.1003052107

34. Diebold, U. Surf. Sci. Rep. 2003, 48, 53-229. doi:10.1016/S0167-5729(02)00100-0

35. Diebold, U.; Li, M.; Dulub, O.; Hebenstreit, E. L. D.; Hebenstreit, W. Surf. Rev. Lett. 2000, 7, 613-617. doi:10.1142/S0218625X0000052X

36. Sanjinés, R.; Tang, H.; Berger, H.; Gozzo, F.; Margaritondo, G.; Lévy, F. J. Appl. Phys. 1994, 75, 2945-2951. doi:10.1063/1.356190

37. Wendt, S.; Schaub, R.; Matthiesen, J.; Vestergaard, E. K.; Wahlström, E.; Rasmussen, M. D.; Thostrup, P.; Molina, L. M.; Lægsgaard, E.; Stensgaard, I.; Hammer, B.; Besenbacher, F. Surf. Sci. 2005, 598, 226-245. doi:10.1016/j.susc.2005.08.041

38. Wendt, S.; Sprunger, P. T.; Lira, E.; Madsen, G. K. H.; Li, Z.; Hansen, J. Ø.; Matthiesen, J.; Blekinge-Rasmussen, A.; Lægsgaard, E.; Hammer, B.; Besenbacher, F. Science 2008, 320, 1755-1759. doi:10.1126/science.1159846

39. Nakaruk, A.; Reece, P. J.; Ragazzon, D.; Sorrell, C. C. Mater. Sci. Technol. 2010, 26, 469-472. doi:10.1179/026708309X12468927349299

40. Chung, C. K.; Chuang, K. P.; Cheng, S. Y.; Lin, S. L.; Hsie, K. Y. J. Alloys Compd. 2013, 574, 83-87. doi:10.1016/j.jallcom.2013.04.045

41. Jin, C.; Liu, B.; Lei, Z.; Sun, J. Nanoscale Res. Lett. 2015, 10, 95. doi:10.1186/s11671-015-0790-x

42.Zhang, W. F.; Zhang, M. S.; Yin, Z.; Chen, Q. Appl. Phys. B 2000, 70, 261-265. doi:10.1007/s003400050043

43. Zhang, W. F.; Zhang, M. S.; Yin, Z. Phys. Status Solidi A 2000, 179, 319-327. doi:10.1002/1521-396X(200006)179:2<319::AID-PSSA319>3.0.CO;2$\mathrm{H}$

44. Zhao, Y.; Li, C.; Liu, X.; Gu, F.; Jiang, H.; Shao, W.; Zhang, L.; He, Y. Mater. Lett. 2007, 61, 79-83. doi:10.1016/j.matlet.2006.04.010
45. Gupta, S. K.; Desai, R.; Jha, P. K.; Sahoo, S.; Kirin, D.

J. Raman Spectrosc. 2010, 41, 350-355. doi:10.1002/jrs.2427

46. Pugachevsky, M. A. J. Appl. Spectrosc. 2012, 79, 834-837. doi:10.1007/s10812-012-9680-5

47. Choudhury, B.; Choudhury, A. Phys. E (Amsterdam, Neth.) 2014, 56, 364-371. doi:10.1016/j.physe.2013.10.014

48. Rajabi, M.; Shogh, S.; Iraji zad, A. J. Lumin. 2015, 157, 235-242. doi:10.1016/j.jlumin.2014.08.035

49. Bavykin, D. V.; Gordeev, S. N.; Moskalenko, A. V.; Lapkin, A. A.; Walsh, F. C. J. Phys. Chem. B 2005, 109, 8565-8569. doi:10.1021/jp050762m

50. Zhang, H.; Zhou, M.; Fu, Q.; Lei, B.; Lin, W.; Guo, H.; Wu, M.; Lei, Y. Nanotechnology 2014, 25, 275603. doi:10.1088/0957-4484/25/27/275603

51. Salari, M.; Aboutalebi, S. H.; Aghassi, A.; Wagner, P.; Mozer, A. J.; Wallace, G. G. Phys. Chem. Chem. Phys. 2015, 17, 5642-5649. doi:10.1039/C4CP03177F

52. Sasaki, T. Supramol. Sci. 1998, 5, 367-371. doi:10.1016/S0968-5677(98)00033-9

53. Santara, B.; Giri, P. K.; Imakita, K.; Fujii, M. Nanoscale 2013, 5, 5476-5488. doi:10.1039/c3nr00799e

54. Rodrigues, J.; Peres, M.; Fernandes, A. J. S.; Graça, M. P. F.; Sobolev, N. A.; Costa, F. M.; Monteiro, T. Appl. Surf. Sci. 2012, 258, 9143-9147. doi:10.1016/j.apsusc.2011.08.109

55. Amekura, H.; Umeda, N.; Sakuma, Y.; Kishimoto, N.; Buchal, C. Appl. Phys. Lett. 2005, 87, 013109. doi:10.1063/1.1989442

56. Amekura, H.; Umeda, N.; Sakuma, Y.; Plaksin, O. A.; Takeda, Y.; Kishimoto, N.; Buchal, C. Appl. Phys. Lett. 2006, 88, 153119. doi:10.1063/1.2193327

57. DeLoach, J. D.; Aita, C. R. J. Vac. Sci. Technol., A 1998, 16, 1963. doi:10.1116/1.581204

58. Kitson, S. C.; Jonsson, P.; Rarity, J. G.; Tapster, P. R. Phys. Rev. A 1998, 58, 620-627. doi:10.1103/PhysRevA.58.620

59. Knorr, F. J.; Zhang, D.; McHale, J. L. Langmuir 2007, 23, 8686-8690. doi:10.1021/la700274k

60. Mercado, C.; Seeley, Z.; Bandyopadhyay, A.; Bose, S.; McHale, J. L. ACS Appl. Mater. Interfaces 2011, 3, 2281-2288. doi:10.1021/am2006433

61. Mathew, S.; Kumar Prasad, A.; Benoy, T.; Rakesh, P. P.; Hari, M.; Libish, T. M.; Radhakrishnan, P.; Nampoori, V. P. N.; Vallabhan, C. P. G. J. Fluoresc. 2012, 22, 1563-1569. doi:10.1007/s10895-012-1096-3

62. Evans, C. C.; Liu, C.; Suntivich, J. Opt. Express 2015, 23, 11160-11169. doi:10.1364/OE.23.011160

63. Park, J.; Ozdemir, S. K.; Monifi, F.; Chadha, T.; Huang, S. H.; Biswas, P.; Yang, L. Adv. Opt. Mater. 2014, 2, 711-717. doi:10.1002/adom.201400107

64. Subramania, G.; Lee, Y.-J.; Fischer, A. J.; Koleske, D. D. Adv. Mater. 2010, 22, 487-491. doi:10.1002/adma.200902264

65. Khalid, A.; Chung, K.; Rajasekharan, R.; Lau, D. W. M.; Karle, T. J.; Gibson, B. C.; Tomljenovic-Hanic, S. Sci. Rep. 2015, 5, 11179. doi:10.1038/srep11179

66. Su, J.; Zou, X.; Chen, J.-S. RSC Adv. 2014, 4, 13979-13988. doi:10.1039/c3ra47757f

67. Rex, R. E.; Knorr, F. J.; McHale, J. L. J. Phys. Chem. C 2015, 119, 26212-26218. doi:10.1021/acs.jpcc.5b09005 


\section{License and Terms}

This is an Open Access article under the terms of the Creative Commons Attribution License

(http://creativecommons.org/licenses/by/4.0), which permits unrestricted use, distribution, and reproduction in any medium, provided the original work is properly cited.

The license is subject to the Beilstein Journal of Nanotechnology terms and conditions:

(https://www.beilstein-journals.org/bjnano)

The definitive version of this article is the electronic one which can be found at:

doi:10.3762/bjnano.9.100 